attended by severe brow headache and symptoms of cellulitis of the orbit.

One case of chronic choroiditis and complete amaurosis, the companion eye being affected with choroiditis.

One case of chronic ophthalmitis, the fellow eve being affected with retinal congestion. In every case, excepting one, the excision afforded an unequivocal advantage to the patient.

Adhesion of the Eyelid to the Globe. In two cases in which after a burn the evelid had become rather extensively adherent to the globe, Mr. Solomon dissected back the con necting band, and passed three fine sutures through its free extremity. The dissection has continued rather more posteriorly than where the conjunctival fold exists in the healthy eye; just behind this point, a narrow slit was made througl the substance of the lid, through which the apex of the flap was drawn out and secured in position by means of the sutures which had been previously passed through the wound. In this manœuvre the flap was doubled upon itself, and made to supply the place of the conjunctival fold that the burn hai destroyed, and at the same time to oppose its unabrader mucous surface to the cut conjunctiva of the globe. In one case, as the connecting band was short, Mr. Solomon slit up the outer commissure for a short distance, without which this plan of operating could not have been carried out. In each case chloroform was administered; and with a view to keep the parts at rest, the globe was secured in an inverted position by means of a ligature passed through a slip of conjunctiva near the outer rim of the cornea and the integument on the bridge of the nose.

\section{Olitainal Commmnitations.}

\section{A FEW REMARKS ABOUT SQUINT, ESPECIALLY EXTERNAL SQUIN'T.}

By Haynes Waltox, Esq., Surgeon to St. Mary's Hospital, and to the Central London Ophthalmic Hospital.

THERE are not a few medical men who doubt that strahismus may be removed by an operation; that is not to be wondered at. It would not be difficult to find a goodly number who question the virtues of orthopædic practice, and several other long recognised and valuable additions to practical surgery. Within a few weeks I operated, in private, on a case of internal squint, in the presence of a modern surgeon, to my entire satisfaction, and with the best results. My medical brother, as I supposed, was pleased; but his real sentiments were conveyed to me on our way to town, by this question, asked with great solemnity: "Without any reserve, do you really think that the operation will benefit the child?" It would certainly be easier to deal with an oblique eye, or, perhaps, most phrsi cal deformities, than with this gentleman's prejudices. jut many, who are even well acquainted with the beautiful result now obtained in this variety of the affection, think that $e x$ ternal squint is never remediable. It is to combat this in particular, to publish a few facts, and endeavour to counteract to some exterit, an impression which is more or less abroad, of my discountenancing surgical treatment, that I write.

The external, as compared to the internal abnormal position of the eye, is rare, and it is undeniable, that with this absolute numercal disparity, there is a relatively less number that are admissible for an operation, that is, in which success can reasonably be expected. As in convergent squint, one ere may be affected, or both be involved; but, unlike it, the detection of the single or the double implication can be so readily, and unerringly made out, that there is not the same necessity for certain indispensable tests.

I avoid going into the pathology of strabismus, as it is quite beyond the scope of this short, and, as it is intended, practical communication.

The class of cases in which the greatest relief can be afforded, is that in which one eye only is turned out, and the vision is but slightly affected; and the less this function is interfered with the more certainly will operative treatment be beneficial. But the great criterion for our guidance in the selection of cases, that is on which our prognosis should be founded, is the manner in which the eye can be righted, when the other is covered, or closed. When I find that it can be brought to the centre of the orbit, and maintained there; and, above all, if it can be so kept for a few seconds after the other has been opened, I strongly recommend an operation. I give equally strong assurances of success, when without the sound eye being closed, the deformed one can be brought parallel with its fellow, and so kept for a short period.

During this week, I have had the satisfaction of examining a young woman, on whom I operated several months ago, through the recommendation of $\mathrm{Mr}$. Ellison, of Windsor, whose case was of this latter favourable lind. A well marked squint had existed eight or nine years, and the eye was presby opic or long-sighted. I operated in expectation of the fullest benefit. An immediate improvement followed, but perfect parallelism was not restored. Now this partial effect is the usual occurrence in external squint; I looked for it, and with patien expectation awaited the completion. At the end of a week, when I dismisserl her, the natural position had nearly been attained; and now, after the lapse of four months, I find as great perfection as can possibly be accomplished. I defy any one to tell, from mere appearances, that the eye had ever squinted, or that a surgical operation had been done. Thereis almost complete restoration of sight.

Under less encouraging circumstances I often recommend surgical treatment, well knowing that even when the highest resuit cannot be accomplished, improvement will ensue. There are, however, cases, such for instance in which the eversion is so extreme, and the power of inversion so limited, and with which I have never failed to find a very defective retina, that I should decline to interfere. Three weeks ago I operated successfully, in private, in the presence of Dr. Sieveling and Mr. Farrant, on a young lady of eighteen, who had squinted two years. She could not see to read the largest typewith the eve affected, nor could she recognise acquaintances; but she could bring the eye to the centre of the orbit, and maintain it there so long as she directed the sound one to any distant object.

Concerning double external squint, the results of operations have been less satisfactory, because the circumstances under which I have operated, and which are those that are, I believe, nsually met with in the double affection, are less promising. Yet when the eyes are involved in an equal degree, and either can be singly used, and made straight, the double operation may be contidently undertaken. Like the solitary deformity, there are less favourable states which will yield less perfect ends.

The last double operation I did at the Ophthalmic Hospital, but a fortnight ago, was no less pleasing to myself, and those of my collearues that assisted me, than to the patient, a woman twenty-five years old, who said she had squinted since quite a girl. She used one eye at a time, and employed either apparently indiscriminately. She saw only distinctly enough to do coarse needlework, and blundered over small type, but could read large characters. In fourteen days after the operation she could read and work better, and the eyes were as nearly as possible in unison with their movements. Sometimes I detected a very slight inequality, but so slight, that it was not likely to be remarked by a casual observer.

I operate in this manner. Having retracted the eyelids with the double spring wire retractor, I make, just over the insertion of the external rectus, a short vertical slit in the conjunctiva and the subconjunctival tissue, which latter may be so thin as scarcely to be recosnised, or so dense as to demand attention and carefulness in cutting through it. Then I introduce the blunt hook below the muscle, which I secure and sever close to the sclerotica. I complete the process by bringing the edges of the conjunctival wound together by one or two sutures; if a single one does not affect the desired adjustment, I apply a second. This does not cause the slightest irritation, and possesses all the advantages that are to be got from the accurate closing of incised wounds, as compared with tearing them open. I do not practise the so called subconjunctival division of the muscle, as suggested by Monsieur Guérin, for internal squint, by which he hoped to overcome the dropping of the caruncle, and other defects arising from extensive dissections at the corner of the eve, so common at that time. As my opinions on this point have been made so public by the reporters of the several medical journals, as well as by some of my pupils, I consider it useless to advance them here. My objections to it must be tolerably well known. I would merely say, for the benefit of those who are as yet beginners in ophthalmic surgery, and may feel disposed, from what they have heard of Guerin's operation in internal squint, to try it, (and I am sure if they do that they will be disappointed), that the theory does not apply to an operation on the external rectus, and that the different anatomical disposition of the parts about the outside of the eye, renders the division of the muscle by the French system still more uncertain. 